\title{
PARA COMPRENDER LA RELACIÓN \\ ENTRE LA CONSTITUCIÓN DE ESTADOS UNIDOS Y LA REGLA DE RECONOCIMIENTO CONVENCIONAL*
}

\author{
UNDERSTANDING THE RELATIONSHIP BETWEEN THE U.S. \\ CONSTITUTION AND THE CONVENTIONAL RULE \\ OF RECOGNITION
}

\section{Kenneth EINAR HIMMA**}

\section{Resumen:}

Los teóricos del derecho que se especializan en teoría constitucional usualmente han considerado que el positivismo y otras teorias conceptuales son irrelevantes; la idea es que una teoría sobre el concepto de derecho no puede decirnos nada que ayude a resolver cuestiones sustantivas normativas y descriptivas de la teoría constitucional. Aunque hay algo de cierto en esta queja, existe cuando menos una cuestión sustantiva no-normativa que vale la pena investigar, e intento hacerlo en esta contribución. En este sentido, el propósito de este artículo es examinar la relación entre la Constitución de los Estados Unidos de América y la noción de regla de reconocimiento propuesta por H.L.A. Hart, a partir de las prácticas de los oficiales. Esto quizá no resuelve ningún problema interesante de teoría constitucional, pero sirve de base para asumir que la supremacía judicial se extiende más allá de lo que comúnmente se asu-

* Artículo recibido el 12 de noviembre de 2014 y aceptado para su publicación el 29 de noviembre de 2014.

** Traducción de Pedro Villarreal Lizárraga, alumno del Programa de Doctorado del Instituto de Investigaciones Jurídicas de la UNAM, pedroav84@gmail.com. Este artículo fue publicado en inglés por primera vez bajo el título "Understanding the Relationship between the U.S. Constitution and the Conventional Rule of Recognition" en Adler, Matthew D. y Himma, Kenneth Einar (eds.), The Rule of Recognition and the U.S. Constitution, Oxford University Press, Oxford (Reino Unido), 2009. 
Este libro forma parte del acervo de la Biblioteca Jurídica Virtual del Instituto de Investigaciones Jurídicas de la UNAM www.juridicas.unam.mx

KENNETH EINAR HIMMA

me, lo que conlleva que las cuestiones normativas morales relacionadas con esta práctica en un sistema democrático de gobierno sean todavía más difíciles.

\title{
Palabras clave:
}

Positivismo, Constitución, constitucionalismo, interpretación constitucional, supremacia judicial, regla de reconocimiento.

\begin{abstract}
:
Legal theorists specializing in constitutional theory have tended to regard positivism and other conceptual theories as irrelevant; the idea is that a theory of the concept of law cannot tell us anything that helps to solve difficult normative and descriptive substantive issues of constitutional theory. While there is something to this complaint, there is at least one substantive non-normative issue worth pursuing - and I attempt to pursue it here. In particular, I attempt to determine how the Constitution and rule of recognition are related by examining the practices of officials. This may not solve any interesting issues of constitutional theory, but it entails that judicial supremacy extends further than is commonly assumed, making the morally normative issues associated with this practice in a democratic system of governance even more difficult.
\end{abstract}

Keywords:

Positivism, Constitution, Constitutionalism, Constitutional Interpretation, Judicial Supremacy, Rule of Recognition. 


\section{LA CONSTITUCIÓN DE E.U. Y LA REGLA DE RECONOCIMIENTO}

SumARIO: I. Fundamentos conceptuales del positivismo. II. La Relación Lógica entre los Criterios de Validez y la Regla de Reconocimiento Social. III. Para identificar los Criterios de Validez y la Regla de Reconocimiento: La Limitación del Ejemplo. IV. La Suprema Corte de los Estados Unidos de América y la Naturaleza de la Autoridad Final. V. La regla de reconocimeinto y la Constitución. VI. Bibliografia.

Los teóricos del derecho que se especializan en la teoría constitucional han tendido a considerar al positivismo y a otras teorías conceptuales como irrelevantes. La idea es que una teoría del concepto de derecho no puede ofrecernos nada que ayude a resolver cuestiones sustanciales sobre teoria constitucional.

Hay algo de cierto en esta queja. Una teoría sobre el concepto de derecho simplemente pone al descubierto las implicaciones metafísicas de los compromisos sociales que gobiernan el uso del término-concepto "derecho", y nos dicen cómo distinguir algo que es derecho de algo que no lo es. Pero el saber cómo llevar esto a cabo no parece ayudar a responder las preguntas normativas que típicamente plantean los teóricos constitucionales: no ayuda a responder la pregunta sobre cómo la Constitución es interpretada de forma adecuada, ni la de quién debería decidir qué es lo que significa la Constitución. ${ }^{1}$ Lo único que el análisis de un concepto puede decirnos es cómo identificar las cosas a las que les es aplicable, pero nuestra comprensión pre-teórica del concepto, por sí misma, es usualmente suficiente para hacerlo. Los jueces y los

1 Por supuesto, hay algunas cuestiones no-normativas que el análisis conceptual puede ayudar a resolver. Por ejemplo, los teóricos del derecho están en desacuerdo sobre si los argumentos para los principios interpretativos tienen un carácter moral o jurídico. Un análisis conceptual podría ayudar a resolver este desacuerdo, pues quizá los teóricos se confunden en cuanto a dónde está la línea entre lo moral y lo jurídico. Pero, entonces, para responder a las preguntas normativas sustantivas que realmente importan - p.ej., cómo deberíamos interpretar la Constitución- uno tendría que emprender el análisis normativo apropiado. 
abogados postulantes lo hacen todo el tiempo sin tener una teoría conceptual del derecho muy acabada.

Aun así, hay al menos una cuestión sustantiva no-normativa sobre la que vale la pena abundar, y lo pretendo hacer en estas líneas. En específico, pretendo determinar cómo se relacionan la Constitución y la regla de reconocimiento al examinar las prácticas de los oficiales. Esto no resolverá ningún problema interesante sobre teoría constitucional, pero implica que la supremacia judicial se extiende más allá de lo que comúnmente se asume, lo que dificultará todavía más las cuestiones moralmente normativas que se asocian a esta práctica en un sistema de gobierno democrático.

\section{Fundamentos CONCEPTUALES DEL POSITIVISMO}

\section{El concepto de los criterios de validez}

La tesis metafísica según la cual en cualquier sistema jurídico posible, hay ciertas propiedades que constituyen a una norma como derecho (exactamente de la misma manera en que la circunstancia de no estar casado constituye a un hombre como soltero) es fundamental para un análisis conceptual del derecho. Cualquier norma que presente las propiedades adecuadas es, por esta razón, considerada como derecho en un sistema jurídico; cualquier norma que no presente las propiedades correctas no es, por la misma razón, considerada como derecho en un sistema jurídico.

Una consecuencia de esta idea es que en cada sistema jurídico conceptualmente posible existen condiciones necesarias y suficientes para que una norma sea considerada derecho. Si $S$ es un sistema jurídico y $P$ es un enunciado que describe las propiedades que le proporcionan a una norma el carácter de derecho, ${ }^{2}$ entonces $P$ señala los crite-

$2 P$, por supuesto, podría expresar una lista complicada de propiedades que incluyen disyunciones o conjunciones. 


\section{LA CONSTITUCIÓN DE E.U. Y LA REGLA DE RECONOCIMIENTO}

rios necesarios y suficientes de "validez jurídica" de $S$ en el siguiente sentido:

La Tesis de Diferenciación: En cada sistema jurídico conceptualmente posible $S$, hay un grupo de $C d V$ (es decir, "criterios de validez") de tal modo que, por cada norma $n$, $n$ es una ley en $S$ en el momento $t$ si y sólo si $n$ satisface los $C d V$ en $t$.

Hay un par de observaciones que vale la pena plantear sobre la Tesis de Diferenciación. Primero, la Tesis de Diferenciación es una tesis metafísica y no epistemológica. La Tesis de Diferenciación no presupone ni implica afirmación alguna sobre la medida en la que pueden identificarse los criterios de validez de un sistema. Segundo, la Tesis de Diferenciación, en tanto es derecho, no implica nada sobre las relaciones conceptuales entre derecho y moral. El contenido jurídicamente válido puede estar $-\mathrm{O}$ no- necesariamente limitado por principios morales, o bien por el carácter inherentemente interpretativo del derecho. Hasta ahora, todo teórico conceptual ha adoptado la Tesis de Diferenciación.

\section{La Tesis de la Separabilidad}

La Tesis de la Separabilidad, según se entiende aquí, niega la afirmación de San Agustín de que las normas injustas no pueden ser derecho. Si bien San Agustín creía que el derecho debe estar conforme con los principios morales, la Tesis de la Separabilidad afirma que puede haber sistemas jurídicos con criterios de validez que no implican una conformidad con los principios morales. En otras palabras, puede haber tanto sistemas jurídicos perversos como leyes perversas - como la Alemania Nazi, el apartheid en Sudáfrica y los Estados Unidos de América antes de la Guerra Civil-.

Si se le interpreta de esta manera, la Tesis de la Separabilidad no niega que haya relaciones necesarias entre el derecho y la moral; simplemente, excluye una relación particularmente necesaria entre el derecho y la moral - específicamente, una conexión necesaria entre los criterios para determinar lo 
que se considera derecho y los relacionados con los principios morales-. Los positivistas a menudo han reconocido otras relaciones necesarias entre el derecho y la moral. H.L.A. Hart señala que el derecho tiene que incluir "el contenido mínimo de derecho [moral] natural" para que aspire a su propósito conceptual de guiar la conducta. Joseph Raz sostiene que esto permite la existencia de una cooperación social que, de otro modo, no sería posible tener entre los que no son ángeles $\mathrm{y}$, por ende, desempeña una función claramente moral.

\section{La Tesis Social}

De acuerdo con la Tesis Social, lo que en esencia distingue a las normas jurídicas de las no-jurídicas es que aquéllas ejemplifican una propiedad que hace referencia a algún hecho social. Entonces, el hecho social relevante es lo que en última instancia explica la existencia de un sistema jurídico y lo constituye como un artefacto social.

Según la postura de Hart, lo que crea la existencia de un sistema jurídico es la presencia de una regla de reconocimiento que proporciona recetas para crear, implementar, modificar, acordar y adjudicar el derecho, y que a su vez produce leyes que regulan efectivamente la conducta de los ciudadanos. Además, para Hart hay un sistema jurídico en $S$ cuando (1) los oficiales en $S$ practican los criterios de validez definidos por la regla de reconocimiento; y (2) los ciudadanos en $S$ generalmente obedecen las reglas de primer orden validadas por la regla de reconocimiento. Las propiedades (1) y (2) son los hechos sociales que le dan origen al derecho y, por lo tanto, son las que constituyen al derecho como un artefacto.

\section{La Tesis de Convencionalidad}

La Tesis de Convencionalidad explica el contenido y autoridad de los criterios de validez en cada sistema jurídico conceptualmente posible en términos de una convención social practicada por las personas que se desempeñan 


\section{LA CONSTITUCIÓN DE E.U. Y LA REGLA DE RECONOCIMIENTO}

como oficiales. Tal como se le utiliza aquí, el término "convención” es utilizado para elegir lo que Hart denomina una "regla social" - y no una convención de coordinación, en el sentido en que David Lewis emplea el término-. Las reglas sociales tienen un "aspecto externo" y un "aspecto interno". El aspecto externo consiste en miembros del grupo que ajustan su conducta a una regla, a tal grado que puede ser descrito en términos de efectuarlo "como una regla" . El aspecto interno consiste en que los miembros del grupo convergen en una actitud reflexiva crítica que los constituye como normativos en el sentido de que desviaciones de esa regla son criticados de manera apropiada.

Desde la perspectiva de Hart, las normas, si son entendidas como reglas sociales, pueden establecer obligaciones, pero no necesitan hacerlo. De acuerdo con Hart, las reglas o convenciones sociales que definen obligaciones tienen las siguientes características: (1) las personas en el grupo social relevante ajustan su conducta a las acciones requeridas por las reglas; (2) las personas en el grupo de críticos manifiestan una actitud reflexiva crítica hacia el interior al cuestionar las desviaciones de esa regla; y (3) se ejerce una alta presión social sobre las personas para que se apeguen a la regla y eviten desviaciones inexcusables o injustificadas.

De acuerdo con la Tesis de Convencionalidad, el derecho existe cuando hay una regla de reconocimiento social que resulta en la regulación eficaz de la conducta de los ciudadanos. Tal como Hart expresa este punto, "las reglas de conducta válidas según el criterio de validez último del sistema tienen que ser generalmente obedecidas, y... sus reglas de reconocimiento que especifican los criterios de validez jurídica, y sus reglas de cambio y adjudicación, tienen que ser efectivamente aceptadas por sus funcionarios como

3 Énfasis en el original. Hart, H. L. A., The Concept of Law, 2a. ed. Oxford, Clarendon Press, 1994, p. 55 [Hay traducción al español, Hart, H. L. A., El concepto de derecho, 2a. ed., trad. Genaro R. Carrió, México, Editorial Nacional, 1980]. 
pautas o ejemplos públicos y comunes de conducta oficial”. ${ }^{4}$ Aunque algunos positivistas piensan que la regla de reconocimiento no es más que una costumbre judicial, esto es incorrecto. El alcance de la autoridad de un tribunal se encuentra limitado, por ejemplo, por la aceptación de los oficiales que tienen autoridad para implementar el derecho. Si los oficiales se niegan a respaldar un grupo de decisiones de los tribunales con la fuerza policíaca del Estado, entonces esas decisiones carecen de las consecuencias normativas que el derecho debe tener como cuestión conceptual, isi es que va a ser considerado derecho en el sentido positivista de la palabra! Dado que la autoridad jurídica de los tribunales está limitada por su aceptación por los demás oficiales, la existencia y el contenido de la regla de reconocimiento dependen de las prácticas conjuntas tanto de los jueces como de los otros oficiales.

\section{LA RELACIÓN LÓGICA ENTRE LOS CRITERIOS DE VALIDEZ Y LA REGLA DE RECONOCIMIENTO SOCIAL}

Los términos "criterios de validez" y "regla de reconocimiento" no son sinónimos. Mientras que la regla de reconocimiento social es al menos en parte normativa, que es lo que uno puede esperar de las reglas, los criterios de validez tienen un cáracter puramente descriptivo. En efecto, los criterios de validez (i.e. los criterios que distinguen lo que es derecho de lo que no lo es en un sistema jurídico) son usualmente expresados por enunciados bicondicionales sin lenguaje normativo alguno:

Esquema de Criterios de Validez: X es una ley en $\mathrm{S}$ si y sólo si X se ajusta a las condiciones establecidas por la proposición $P$, donde $P$ es un conjunto de propiedades.

4 Hart, H. L. A., The Concept of Law, cit., p. 113 [consultable en la traducción en la p. 145]. 
Un enunciado con esta forma ni es una norma, ni tiene los recursos para otorgar razones para la acción porque carece de un lenguaje deóntico capaz de dar tales razones.

En cambio, la regla de reconocimiento se expresa en términos deónticos que describen o definen obligaciones y deberes. Así, las normas de reconocimiento tienen la siguiente forma:

Esquema de Regla de Reconocimiento: Un presidente/legislador/juez tiene un deber (o deberia) de realizar $\mathrm{X}$ en ejecución de su función de presidente/legislador/juez.

A diferencia del Esquema de Criterios de Validez, el de Regla de Reconocimento contiene recursos lógicos - esto es, nociones deónticas- que definen y expresan deberes.

Los criterios de validez puramente descriptivos son extrapolados de un estudio de las reglas de reconocimiento normativas, particularmente aquellas que requieren de ciertos actos como precondición para crear derecho. Claramente, las normas de reconocimiento que definen deberes directamente respecto de reconocer, crear y adjudicar el derecho, así como aquellas que confieren el poder para hacerlo, determinarán las propiedades que necesita una norma para tener el status de derecho.

Aunque la "regla de reconocimiento" y los "criterios de validez" están intimamente relacionados, aun así es importante distinguir los dos porque, como lo veremos más adelante, hay algunas normas de reconocimiento que definen deberes relativos a la manera en que la Corte interpreta la Constitución que, en sentido estricto, no son parte de los criterios de validez. Los dos términos están relacionados sin ser sinónimos.

\section{PARA IDENTIFICAR LOS CRITERIOS DE VALIDEZ Y LA REGLA DE RECONOCIMIENTO: LA LIMITACIÓN DEL EJEMPLO}

La noción de Hart de que la existencia y contenido de la regla de reconocimiento son determinados por la práctica de los oficiales conlleva que los criterios de validez son 
aquello que los oficiales conscientemente tratan como tal. Si bien los oficiales en lo individual -incluyendo los juecespueden supuestamente tener creencias equivocadas sobre los criterios de validez, conforme a la Tesis de Convencionalidad simplemente no es posible que los oficiales del sistema jurídico, considerados de forma colectiva, estén generalmente equivocados respecto de algún criterio de validez social. Si todos los oficiales conscientemente reconocen y tratan a las normas que satisfacen $N$ como derecho válido y la autoridad de $N$ se basa en la aceptación, entonces $N$ representa un criterio de validez en $S$. Las propiedades que los oficiales colectivamente consideran como las que constituyen a las normas como jurídicamente válidas, en términos conceptuales son las propiedades que se incorporan a la regla de reconocimiento social que define los criterios de validez jurídica.

Cada característica que constituye una regla social es empíricamente observable. En primer lugar, podemos constatar empiricamente una convergencia en la conducta. Segundo, podemos constatar en los mismos términos que se promueve la conformidad con la regla y que las desviaciones son criticadas. Tercero, podemos constatar, de igual manera, que se ejerce una alta presión social sobre los participantes del grupo para que se ajusten a la regla. Aunque es posible ocultar estas características, los sistemas jurídicos, como el de los Estados Unidos de América, no hacen intento alguno en ese sentido.

En consecuencia, si la Tesis de Convencionalidad de Hart es verdadera, entonces el proyecto de identificar los criterios de validez es empírico. La única manera de identificar el contenido de la regla de reconocimiento social y los criterios de validez es a través de medios empíricos. Para identificar el contenido de los criterios de validez en cualquier sociedad particular, uno debe emplear más o menos los mismos tipos de herramientas empíricas que son comúnmente utilizadas por los sociólogos para estudiar la conducta de los oficiales. Así, conforme a lo que yo llamo la Limita- 


\section{LA CONSTITUCIÓN DE E.U. Y LA REGLA DE RECONOCIMIENTO}

ción del Ejemplo (Modeling Constraint), una descripción correcta de los criterios de validez en un sistema jurídico $S$ tiene que expresar aquellas propiedades que los oficiales colectivamente reconocen como algo que da lugar a normas jurídicamente válidas que están obligados a implementar, a manera de un hecho empírico observable.

\section{La Suprema CoRTe de los Estados Unidos de AmÉRICA Y LA NATURALEZA DE LA AUTORIDAD FINAL}

Hay una serie de puntos controvertidos en torno a la autoridad que tiene la Corte Suprema para resolver asuntos constitucionales. Por ejemplo, los teóricos están en desacuerdo sobre si, hablando en términos de moral política, los tribunales en una sociedad democrática deberian tener la autoridad final para declarar que un decreto debidamente promulgado es inconstitucional. Los téoricos también disienten sobre si, en términos de una cuestión jurídica descriptiva, la Constitución le concede a la Corte la autoridad final sobre una clase particular de asuntos.

Sin embargo, de inicio es importante recalcar que una cosa queda clara: la Corte Suprema actualmente tiene la autoridad final para resolver al menos algunos asuntos constitucionales. En efecto, uno no podría negar de forma plausible que, por ejemplo, la Corte Suprema de los Estados Unidos de América "tiene la última palabra sobre si los estados pueden ejecutar a los asesinos o prohibir los abortos o instaurar la oración en las escuelas públicas y cuándo pueden hacerlo, o bien sobre si el Congreso puede ordenar el reclutamiento de soldados para luchar en una guerra u obligar a un presidente a que haga públicos los secretos de su gestión."5

Ciertamente, dicha autoridad es limitada. Por ejemplo, la Corte carece de autoridad para anular la destitución de los oficiales gubernamentales o nulificar las enmiendas. Pero la

5 Dworkin, Ronald, Law's Empire, Cambridge, Harvard University Press, 1986, p. 2 [con versión en español, véase Dworkin, Ronald, El imperio de la justicia, trad. de Claudia Ferrari, Barcelona, Gedisa, 1994]. 
tesis no consiste en que la autoridad de la Corte es ilimitada; más bien afirma que, cuando menos, la Corte tiene autoridad final para decidir sobre la constitucionalidad de los actos del Congreso.

No es necesario que los tribunales tengan autoridad final o que su alcance sobre la clase de asuntos relevantes sea ilimitado. Podría ocurrir que tal autoridad se distribuya a lo largo de varios departamentos oficiales o incluso entre el pueblo. De igual manera, podría ocurrir que hay algunas cuestiones en las que nadie tiene la autoridad final. No hay ninguna teoría conceptual del derecho que requiera que alguien tenga la última palabra.

1. La capacidad de crear obligaciones juridicas que constriñen a otros oficiales del sistema

Un tribunal tiene autoridad para decidir una cuestión jurídica sustantiva sólo si su decisión crea obligaciones razonables que llevan a que otros oficiales acepten su decisión como derecho. El tener autoridad es ser capaz de emitir directivas que son autoritativas para una categoría relevante de individuos, y una directiva es autoritativa en virtud de que es obligatoria para dicha categoría de individuos.

La autoridad de un tribunal para decidir una cuestión sustantiva de derecho es final si y sólo si no hay una agencia o departamento oficial con autoridad para revocar la decisión del tribunal. Este punto incontrovertido lo explica Dworkin al mencionar que "[un] oficial tiene la autoridad final para tomar una decisión [cuando su decisión] no puede ser revisada ni revocada por algún otro oficial". ${ }^{6}$ En este sentido, si un tribunal tiene autoridad final en una decisión, entonces ésta crea una obligación que constriñe a los oficiales en esa jurisdic-

6 Dworkin, Ronald, Taking Rights Seriously, Cambridge, Harvard University Press, 1977, p. 32 [hay versión en español, véase Dworkin, Ronald, Los derechos en serio, trad. de Marta Guastavino, quinta reimpresión, España, Ariel, 2002]. 


\section{LA CONSTITUCIÓN DE E.U. Y LA REGLA DE RECONOCIMIENTO}

ción; dado que no hay posibilidad de revocación, la obligación es final.

Uno podría considerar que el pueblo es el que tiene autoridad final en una democracia, en el sentido de que pueden promover enmiendas cuyo efecto es el de anular el acto de un oficial y pueden elegir a los oficiales que nombran a los jueces. Aunque esto le otorga a los ciudadanos cierta autoridad que tendría que verse reflejada en una enunciación completa de los criterios de validez, los oficiales practican una regla que le otorga algo de autoridad a las agencias gubernamentales como los tribunales y las legislaturas, y es justamente el contenido de esta autoridad de lo que me ocupo en estas lineas.

Las obligaciones creadas por las decisiones de un tribunal con autoridad final son jurídicas - si bien no moralmente legitimas-. Esto tiene una consecuencia muy importante: En la medida en que un tribunal tiene autoridad final para decidir un asunto sustantivo de derecho, puede constreñir jurídicamente a los oficiales en su jurisdicción a cualquiera de las dos decisiones antagónicas en torno a ese asunto, siempre que las demás cosas permanezcan igual. Por ejemplo, si un tribunal tiene la autoridad final de decidir si los derechos relativos al aborto pueden ser restringidos por una legislación, entonces su decisión crea obligaciones jurídicas que constriñen a otros oficiales sin importar cómo se emite esa decisión - siempre y cuando el tribunal arribe a esta decisión en una manera aceptable-. Así, la Corte Suprema puede constreñir jurídicamente a los otros oficiales con una decisión que puede estar equivocada según la teoría "correcta" de la interpretación (si es que hay alguna).

\section{Autoridad final y discreción del tanteador}

En su contribución, Kent Greenawalt señala que en el béisbol, hay una regla según la cual un bateador es eliminado después de tres 'strikes'; sin embargo, el árbitro (umpire) es el que toma la última decisión. Según su punto de vista, sería 
un error pensar que hay una regla disyuntiva que afirma que estás eliminado o ponchado (out) después de tres 'strikes', o bien después de que el árbitro dice que lo estás, o que hay algún tipo de norma de reconocimiento que autoriza al árbitro a implementar la regla de los tres 'strikes'. De forma similar, sería un error caracterizar a una norma de reconocimiento como la que le confiere autoridad final a la Corte.

Esto no parece ser lo correcto. Las reglas del béisbol son diferentes de, y no incluyen a, la regla de reconocimiento que le da a los árbitros autoridad para tomar decisiones, pero es necesaria alguna regla de reconocimiento que indique quién toma la decisión. Lo anterior queda claro en el contexto del béisbol profesional, el cual contiene un conjunto de reglas de reconocimiento que suplementan a las reglas del béisbol; éstas son fundamentales para el juego, pero las normas de reconocimiento a su vez son fundamentales para saber cuáles normas regirán el béisbol profesional -e incluyen tanto las reglas del béisbol como las que le otorgan a los árbitros la autoridad para implementarlas-.

Hay otra diferencia entre las decisiones del árbitro de béisbol y las de la Corte en cuanto a la constitucionalidad de algún acto. Un árbitro puede declarar el tercer 'strike' de forma equivocada, pero esto no conlleva el anular la regla que dispone que un bateador sea eliminado después de tres 'strikes'. Cuando la Corte anula una regla oficial de forma incorrecta, aun así afecta el status de la regla en una forma distinta a la de los errores de un árbitro, aun cuando el carácter de estos efectos todavía no queda muy claro.

\section{Autoridad final y los criterios de validez}

Aunque es natural pensar que los fallos del tribunal con autoridad final son jurídicamente vinculantes porque establecen el contenido del derecho, esto no es necesariamente cierto. Es tanto lógica como causalmente posible que los oficiales estén jurídicamente obligados a implementar el contenido de una norma que carece del status de derecho, algo que ocurre 


\section{LA CONSTITUCIÓN DE E.U. Y LA REGLA DE RECONOCIMIENTO}

a menudo en disputas que involucran el derecho de alguna otra nación, Estado o jurisdicción.

Pero este no es el modo en el que los oficiales en los Estados Unidos de América comprenden los fallos constitucionales de la Corte de ese país. Aunque los oficiales y los ciudadanos podrían estar en desacuerdo con un fallo de la Corte, al creer que está equivocado en cuestiones de interpretación, ese fallo es aun así tratado y caracterizado como derecho. Aun cuando un fallo es ampliamente percibido como erróneo, el Estado lo implementa con los mismos mecanismos coercitivos que se usan para implementar cualquier otra norma jurídica. Las decisiones de la Corte establecen el contenido del derecho en el ámbito constitucional.

Esto no necesariamente significa que una sentencia de la Corte que declara que una disposición o decreto es inconstitucional lo invalida como derecho, en el sentido de que elimina a esa disposición o decreto de los textos legales o bien le impide a la legislatura volver a promulgar la misma disposición para retar a la Corte a que dé marcha atrás (lo que ocurre bastante a menudo con el caso Roe c. Wade). ${ }^{7}$ Se requiere una derogación explícita de la legislatura para suprimir la disposición de los textos, pero hay pocas razones para que dicho órgano invierta más energías después de que una disposición es declarada inconstitucional. El efecto jurídico de una declaración de inconstitucionalidad y una derogación legislativa es el mismo: la disposición no crea ningún derecho o deber ejecutable. Y lo mismo puede decirse de una nueva promulgación - a menos de que la Corte modifique su criterio en un asunto jurídico subsecuente-.

Los oficiales y los teóricos constitucionales están en desacuerdo en cuanto a cómo caracterizar los efectos de una declaración de inconstitucionalidad. Algunos teóricos y jueces sostienen que el efecto de una declaración de inconstitucionalidad es anular el derecho. En efecto, en el asunto

7 Véase, por ejemplo, Dorf, Michael C. y Adler, Matthew D., "Constitution Existence Conditions and Judicial Review," Virginia Law Review, Vol. 89, 2003, p. 1105. 
Norton c. Condado de Shelby, ${ }^{8}$ la Corte declaró que "un acto inconstitucional no es una ley; no confiere derechos; no impone deberes; en términos jurídicos, es tan inoperante como si nunca hubiese sido emitido." De manera similar, en el caso E.U.A. c. Dickerson, la Corte afirmó: “... el Congreso no puede sustituir legislativamente nuestras decisiones que interpretan e implementan la Constitución." $\mathrm{El}$ caso Dickerson invitó al "Congreso y a los Estados a... buscar... otros procedimientos que sean al menos igual de efectivos en informarle a las personas acusadas sus [derechos]", pero esto era una invitación, efectuada conforme a la discreción de la Corte, a cooperar con los demás órganos oficiales, y no hay nada en la noción de autoridad final que lo impida. ${ }^{10}$

Otros sostienen que tales declaraciones podrian impedir la implementación gubernamental de la ley por las partes del juicio, pero no van más allá. Aquí hay dos argumentos diferentes. Primero, tales decisiones no "nulifican" la ley, porque la disposición tendría efectos sin necesidad de acciones ulteriores por parte de la legislatura, en caso de que la Corte modifique su criterio. Estos teóricos también afirman frecuentemente que los oficiales gubernamentales, que no son parte de la decisión, deberían adecuarse a estas decisiones en aras de evitar actos que probablemente serán

8 Con número de registro 118 U.S. 425, 1886. Para una defensa de esta perspectiva, véase Alexander, Larry y Schauer, Fred, "On Extrajudicial Interpretation", Harvard Law Review, Vol. 110, 1997, p. 1359. Por su parte, la Corte no siempre se ha adherido a esta postura. Véase U.S. $v$. U.S. Coin and Currency, con el registro 401 U.S. 715, 1971, p. 741.

9 Con el número de registro 120 S.Ct. 2326 (2000) en la p. 2332.

10 Véase Dorf, Michael C. y Friedman, Barry, "Shared Constitutional Interpretation", The Supreme Court Review, 2000, p. 61. Aunque Dorf y Friedman defienden la tesis normativa de que debería otorgarse a otros actores políticos alguna función en la construcción del significado constitucional, afirman aun así que la Corte debe tener la última palabra. En efecto, señalan que "no cabe duda de que la Corte es a quien se le asigna la función primaria de determinar el alcance de los derechos constitucionales" y así, parecen adoptar la postura "maximizadora" de la autoridad de la Corte defendida por Alexander y Shauer, nota 8. 


\section{LA CONSTITUCIÓN DE E.U. Y LA REGLA DE RECONOCIMIENTO}

declarados inconstitucionales, dada la postura explícita de la Corte sobre ese tema. ${ }^{11}$

Nada de esto hace mucha diferencia porque la declaración de inconstitucionalidad de una norma por la Corte claramente la vuelve inaplicable y, por lo tanto, la despoja de la fuerza que, en parte, es lo que convierte a una legislación en derecho; las normas de un sistema $S$ que no pueden ser jurídicamente implementadas no son propiamente caracterizadas como "derecho", o como si tuvieran el status de "validez jurídica" o "legalidad". Las normas jurídicas son respaldadas por el poder policíaco del Estado. Cuando aquéllas pierden esta última característica, su status como "derecho", al menos en lo que respecta al positivismo, ha sido eliminado para efectos prácticos — sin importar que permanezcan en los textos jurídicos-.

El segundo argumento es que las decisiones de la Corte crean obligaciones juridicas que vinculan a las partes de un caso, pero no crean obligaciones generales de abstenerse de implementar leyes que han sido declaradas inconstitucionales. ${ }^{12}$ Pero, como cuestión de práctica jurídica, otros oficiales administrativos obedecen el fallo y se niegan a implementar leyes que son declaradas inconstitucionales, así como otras que tienen contenido muy similar, lo que sugiere que hay una alta probabilidad de que también sean

11 Edwin Meese adopta esta postura. Véase, por ejemplo, Meese, Edwin, "The Supreme Court of the United States: Bulwark of a Limited Constitution", South Texas Law Review, vol. 27, 1986, p. 4555. Larry Kramer sostiene en The People Themselves que este tipo de "departamentalismo" puede observarse en Marbury c. Madison y que la moral politica requiere de un retorno a esta comprensión del papel de la Corte al interpretar e implementar la Constitución en relación con otros actores políticos.

12 Véase Fallon, Richard, "As-Applied and Facial Challenges and Third Party Standing", Harvard Law Review, vol. 113, 2000, p. 1339 y ss. Para una postura antagónica, véase Alexander, Larry y Schauer, Fred, "On Extrajudicial Interpretation" , Harvard Law Review, vol. 110, 1997, p. 1359. 
declaradas inconstitucionales. Esta práctica también incluye al presidente.

Aunque hay algunos académicos constitucionalistas que creen que en los Estados Unidos de América no hay un deber jurídico para estos oficiales de abstenerse de implementar tales leyes y adoptar esta práctica, supuestamente por una suerte de cortesía profesional o bien por prudencia, lo cierto es que se ocupan de temas distintos a los del positivista. Los académicos de derecho constitucional discuten sobre una cuestión normativa en torno a la interpretación de la Constitución, específicamente si las decisiones de la Corte Suprema deberian ser interpretadas en el sentido de que crean obligaciones generales, y si ello sería una adecuada interpretación de la Constitución y su historia. Esta es una cuestión normativa que es diferente de la puramente descriptiva que preocupa al positivista - particularmente, si los oficiales convergen en una norma social que los obliga a abstenerse de implementar tales leyes-. Si la respuesta es afirmativa, como parece quedar claro, entonces los oficiales adoptan el punto de vista interno frente a una norma de reconocimiento que crea una obligación jurídica de abstenerse de implementar dichas leyes. ${ }^{13}$ Esa práctica podría cambiar si y cuando los teóricos de derecho constitucional que discuten la cuestión normativa logran llegar a un consenso general de que no hay tal deber jurídico conforme a una adecuada interpretación de la Constitución. Pero, hasta que la práctica en sí misma cambie, los oficiales tratan a los fallos como jurídicamente obligatorios, en especial, como pa-

13 Véase Kramer, Larry, The People Themselves: Popular Constitutionalism and Judicial Review, Oxford, Oxford University Press, 2005. Kramer sostiene que la Corte Suprema ha usurpado la autoridad final, la cual debería ser recuperada por el pueblo. De cualquier modo, a partir de un análisis histórico comprehensivo, la afirmación descriptiva confirma que la práctica oficial hoy en día le confiere la autoridad final respecto de la Constitución a la Corte Suprema; la tesis normativa es que esto es ilegitimo. Pero la cuestión normativa no es relevante para un análisis positivista del contenido de la regla de reconocimiento, aunque es indudablemente importante. 


\section{LA CONSTITUCIÓN DE E.U. Y LA REGLA DE RECONOCIMIENTO}

rece razonable conjeturar, si critican las situaciones en las que otros oficiales ignoran completamente dichos fallos e implementan una ley idéntica a la que fue declarada inconstitucional por la Corte. Los teóricos constitucionales se preocupan del contenido de una adecuada interpretación de la Constitución y no del contenido de la regla de reconocimiento, y éstas son reglas relacionadas pero distintas.

Desde el punto de vista de la filosofia general del derecho, las disposiciones inconstitucionales no son consideradas propiamente como "derecho" porque ya no son implementadas como una práctica general entre los oficiales $\mathrm{y}$, por ende, no dan lugar a derechos u obligaciones jurídicamente ejecutables. De todas formas, así es como los términos 'derecho' y 'validez jurídica' deberían ser entendidos en este punto.

En efecto, los abogados son formados para considerar que los fallos del tribunal que posee la autoridad final son los que establecen el contenido del derecho. Cada recopilación de casos (casebook) de derecho constitucional en los Estados Unidos de América contiene extractos de casos controvertidos de la Corte Suprema que son ampliamente considerados como incorrectos. Por ejemplo, no hay una recopilación o tratado de derecho constitucional en los Estados Unidos de América que no contenga un extracto o discusión del caso Roe. Entre los practicantes, estudiantes y oficiales del sistema jurídico se asume que, para bien o para mal, la decisión de la Corte en el asunto Roe estableció el contenido del 'derecho' (en el sentido apenas desarrollado) relacionado con el aborto en los E.U.A.

Entonces, los oficiales de los E.U.A. recurren a una norma de reconocimiento que les exige considerar que los fallos de la Corte tienen autoridad final para establecer el contenido del derecho en ciertos temas relacionados con la Constitución, aunque esta autoridad, como lo veremos, se encuentra limitada de diversas maneras. No es sólo el que los oficiales se comporten de tal manera. La mayoría, aunque no todos, acepta y practica esta regla porque creen que 
asi lo requieren los principios fundamentales que subyacen a la estructura del sistema jurídico. Pero algunos pueden aceptar la regla por razones puramente prudenciales (digamos, para salir adelante) e incluso creen que no se trata de la mejor regla o que ésta se infiera de tales principios.

\section{Autoridad final y desacuerdos oficiales}

El que los oficiales estén obligados por un fallo no implica que tengan que estar de acuerdo con él; simplemente implica que deben cumplir con él en lo que concierne a los actos relacionados con sus facultades. Por ejemplo, como lo señala Greenawalt, un Senador puede estar en desacuerdo con un fallo que establece que un acto legislativo es constitucional y votar en contra de él al considerarlo inconstitucional cuando se somete a una renovación. Dentro de la tesis según la cual la Corte tiene autoridad final para decidir en los temas constitucionales, no hay nada que implique que cualquier oficial que está obligado por ella tenga que creer que es lo correcto.

Por supuesto, algunos oficiales en veces han negado públicamente la autoridad final de la Corte. En su momento, John Ashcroft, el ex fiscal general de los Estados Unidos de América durante el gobierno de George W. Bush, lo hizo así. El presidente Madison amenazó con desobedecer el fallo de la Corte en el asunto Marbury c. Madison si éste tomaba un rumbo incorrecto. Quizá el ejemplo más ilustrativo es el del caso Brown c. Consejo de Educación. La Corte sostuvo que debía abolirse la segregación en las escuelas públicas con "toda la celeridad posible" para indicarle a los estados sureños que la Corte no iba a ejecutar la decisión inmediatamente, ello como una manera de prevenir una rebelión oficial generalizada en el sur que habría ocasionado la crisis más grave en los Estados Unidos de América desde la Guerra Civil.

Es necesario hacer un par de observaciones sobre este punto. Primero, estas situaciones son demasiado esporádi- 


\section{LA CONSTITUCIÓN DE E.U. Y LA REGLA DE RECONOCIMIENTO}

cas como para justificar las dudas sobre si la Corte tiene autoridad final para decidir la constitucionalidad de una ley. Sin embargo, la situación en torno al caso Brown podría en última instancia haber conducido a una rebelión y, dada la resistencia de los oficiales del sur, podria haberse convertido en una época en la que se derrumbó la práctica social que le otorga a la Corte dicha autoridad final. Toda vez que la Corte no ejecutó su fallo a través de órdenes contundentes de abolir la segregación sino hasta que la cultura en los Estados del sur hubiese cambiado de forma significativa, quizá nunca sabremos cuál era exactamente la práctica social durante ese período.

Segundo, es muy probable que la mayoria de los oficiales que sugirieron que desobedecerian un determinado fallo, lo hubieran obedecido si se les hubiese presionado a hacerlo. Una cosa es que un oficial exprese esa opinión y otra muy diferente es actuar sobre esa base. Las consecuencias de transgredir una práctica social arraigada relacionada con la Constitución son lo suficientemente graves para desalentar a aquellos oficiales que creen que la Corte carece de la autoridad, a fin de que no actúen en esa misma línea. Hablar es barato.

Tercero, aun si algunos oficiales ocasionalmente actúan a partir de esta creencia, ello no afecta el análisis. Un positivista no podría defender que el hecho de que todos los oficiales converjan siempre en sus conductas y actitudes con un contenido específico, es en sí una condición necesaria para la existencia de un sistema jurídico. Si el positivismo defendiera esta posición, la negativa de John Ashcroft de la autoridad final de la Corte sería suficiente, por sí misma, para demostrar que los Estados Unidos de América tienen un sistema jurídico, y este argumento es una reductio de cualquier tesis que arroje este resultado. Lo más que un positivista puede afirmar en este contexto, es que un número suficiente de oficiales convergen cuando menos lo bastante frecuententemente respecto del contenido de una 
norma de reconocimiento, de tal modo que pueden regular efectivamente la conducta de los ciudadanos.

En efecto, no hay nada en la idea de que la Corte tiene autoridad final que indique que un Ministro que disiente con un fallo tiene que abandonar su oposición en la siguiente ocasión en la que surja esa misma controversia. En relación con la cuestión del aborto, el Ministro Scalia ha indicado que "continuará con el disentir del objetivo [de la Corte] de concebir un Código del Aborto, y de la ilusión de que [la Corte tiene] autoridad para hacerlo". ${ }^{14}$ Esto no sólo es consistente con el análisis que se ha ofrecido hasta este punto; como lo veremos, quizá la norma de reconocimiento también requiere que Scalia converja con los demás Ministros en la práctica, particularmente dada la propia postura que él adopta sobre la mejor teoría de interpretación constitucional.

La práctica general es la siguiente: un oficial que se rehusó a ejecutar un fallo del tribunal que posee la autoridad final, al creer que estaba equivocado y que, por lo tanto, no es derecho, provocaría una serie de críticas y una orden judicial para acatar dicho fallo. En la medida en que estas expectativas sean tanto institucionales como normativas, los oficiales practican una norma de reconocimiento que hace que ciertas resoluciones de los tribunales sean determinativas del contenido del derecho, un hecho que determina a su vez el contenido de los criterios de validez.

Pero en la medida en que los oficiales practican una regla que limita a los jueces a decidir cuestiones sustantivas de derecho de acuerdo con $N$, no ejecutarán una decisión que no se encuentre fundamentada putativamente en un intento de satisfacer $N$. Hay un incentivo considerable para que los otros oficiales acaten los fallos del tribunal que tiene autoridad final; en nuestro mundo peligroso, cualquier señal de una ruptura entre las distintas ramas de gobierno puede tener graves consecuencias para la seguridad nacional.

14 Hodgson v. Minnesota, 497 U.S. 417 (1990), p. 480 (voto disidente). 
Aun así, probablemente hay limites para la cooperación de los otros oficiales en las normas de reconocimiento que practican. ${ }^{15}$ Por esta razón, la autoridad del tribunal de constituir los contenidos jurídicos estará usualmente circunscrita a requerimientos de segundo orden, los cuales también encontrarán cabida en enunciados puramente descriptivos sobre los criterios de validez.

Una decisión judicial es suficiente para la legalidad, pero no es necesaria, toda vez que los oficiales pueden tratar una norma debidamente promulgada como derecho por un período extendido sin que haya un procedimiento judicial de por medio. Si los ciudadanos son diligentes en ajustarse a la norma, entonces ésta es caracterizada de forma apropiada como 'derecho' aun sin que haya una confirmación oficial por el tribunal que posee autoridad final. Esta característica de la práctica jurídica complica la labor de resumir las condiciones necesarias y suficientes del derecho, y el lector debería entender desde un inicio que yo no he resuelto tales cuestiones.

\section{Autoridad final y declaraciones de que una ley es constitucional}

Hasta ahora, me he enfocado en declaraciones de la Corte Suprema de que una ley es inconstitucional; sin embargo, hay otras cuestiones adicionales que surgen a partir de esas declaraciones. He sostenido que los oficiales implementan una norma que crea una obligación jurídica de reconocer que una decisión de la Corte (dentro del alcance limitado de su autoridad) determina el contenido del derecho, sin importar el que piensen que la decisión está equivocada o no. Esta es exactamente la razón por la cual la Corte es justamente considerada como la que posee autoridad final, desde el punto de vista de identificar el contenido de la regla de reconocimiento.

15 Por ejemplo, yo supondría que una decisión judicial que estuviese explícitamente fundamentada en el lanzamiento de una moneda, se aproximaria a un colapso entre esa corte y los demás oficiales. 
Pero es importante tener cuidado con este punto. Así como una decisión de la Corte que alguno de los Ministros considera errónea no impide que ese Ministro disienta en la siguiente ocasión en que surja el tema, ni se requiere que el Ministro modifique su voto, tampoco se requiere que un oficial aplique una ley que él o ella cree que es inconstitucional, aunque ello sea contrario a la decisión de la Corte Suprema. Mientras que, como lo señala Frank Easterbrook, hay una práctica de larga data entre los Presidentes de rehusarse a ejecutar disposiciones que ellos creen que son inconstitucionales, ${ }^{16}$ quizá también existe una práctica entre los oficiales, incluyendo los Presidentes, de no implementar las disposiciones que creen que la Corte erróneamente declaró como constitucionales.

Lo apenas expuesto no es incongruente con lo demás que se ha dicho hasta aquí. Ya es bien aceptado el que los oficiales responsables de la ejecución y/o implementación de lo que se considera derecho tienen una considerable discreción en cuanto a si ejecutan o no algo que formalmente tiene el status de 'derecho'. Hay varias disposiciones en los ordenamientos jurídicos que no han sido implementadas por años debido a una creencia de que sería inapropiado hacerlo, pero todavía son considerados formalmente como derecho porque podrían serlo ante la ausencia de algún tribunal que determine lo contrario. Si la Corte declara que una ley es constitucional y el Presidente considera que esto es erróneo, éste tiene la discrecionalidad legal para no implementar esa norma a partir de una creencia de que es inconstitucional. ${ }^{17}$ Pero el sentido general de la práctica oficial es

16 Sobre esto, véase el artículo de Easterbrook, Frank, "Presidential Review", Case Western Reserve Law Review, vol. 40, 1989, p. 905; y Paulsen, Michael Stokes, "The Most Dangerous Branch", Georgetown Law Journal, Vol. 83, 1994, p. 217, particularmente la p. 267 y ss.

17 En efecto, algunos teóricos consideran que si se comprende debidamente a la Constitución, ésta define un deber jurídico por parte del Presidente de no ejecutar tales leyes. Véase la nota 16. Pero, por otra parte, esta es una cuestión distinta a la que yo abordo aquí como positivista. Paulsen se preocupa del asunto normativo sobre qué es lo que la Consti- 
que la referida norma puede ser implementada y, por lo tanto, es considerada como derecho aun si un oficial ejerce su discrecionalidad y no la acata. En este análisis sobre la autoridad final, las decisiones de la Corte no obligan jurídicamente a los oficiales a implementar normas que aquélla declara constitucionales.

\section{LA REGLA DE RECONOCIMIENTO Y LA CONSTITUCIÓN}

Como puede evidenciarse en la sección que antecede, no hay una relación directa entre las reglas de reconocimiento y las constituciones escritas. Primero, un sistema jurídico podría no tener una constitución escrita. Segundo, aun si la tiene, los oficiales podrian no considerarla como obligatoria e ignorarla. Tercero, el texto de una Constitución tiene que ser interpretado, y hay varias teorias diferentes de interpretación constitucional. Para explicar la función que desempeña una Constitución escrita de determinar qué es lo que se considera derecho, tenemos que observar todas las prácticas relevantes de los oficiales en el sistema.

\section{La Limitación del Ejemplo y la Formulación de Incorporación Directa}

Muchos positivistas han asumido que la Constitución de los Estados Unidos de América directamente define criterios de validez. Hart sostiene, por ejemplo, que los "criterios de validez jurídica que la regla proporciona... puede... consistir en limites sustantivos al contenido de legislación como la Decimosexta o Decimonovena Enmienda a la Constitución

tución dispone respecto de las obligaciones legales del Presidente, si se le interpreta de forma adecuada. Yo adopto el objetivo descriptivo de identificar el contenido de la regla de reconocimiento que está siendo practicada por los oficiales. Habrá mucha confusión como resultado de no lograr distinguir estas dos cuestiones. 
de los E.U.A". ${ }^{18}$ De igual manera, Brian Leiter afirma que "[una] regla es jurídicamente válida en los Estados Unidos si ha sido debidamente promulgada por la legislatura federal o alguna estatal y no es inconsistente con la Constitución federal."19 Según esta perspectiva, los Estados Unidos de América contemplan lo siguiente como un criterio de validez:

La Formulación de Incorporación Directa (FID): Una norma debidamente promulgada es jurídicamente válida si y sólo si está conforme con las normas de la Constitución.

La FID afirma que, por ejemplo, si se evidencia de forma objetiva que ciertas normas debidamente promulgadas violan la Primera Enmienda, éstas son inválidas por esa misma razón.

Al evaluar la FID, es útil recordar que los oficiales frecuentemente consideran las decisiones sobre validez de la Corte Suprema como objetivamente equivocadas. Por ejemplo, el fallo de la Corte en el caso Roe c. Wade continúa siendo controvertido, ¡cuarenta y un años después de haber sido resuelto! Muchas personas creen que la decisión del caso Roe es incorrecta como una cuestión de derecho e interpretación constitucional. Mientras que algunos creen que el caso Roe no es consistente con la protección de la Constitución del derecho a la vida de una persona, otros creen que constituyó un nuevo derecho constitucional de forma ilegitima. Entre estos críticos, hay miembros del Congreso, fiscales generales de varios presidentes recientes, y ministros de la Corte Suprema, que son precisamente los oficiales cuyas prácticas determinan el contenido de los criterios de validez.

El problema de la FID es que los oficiales, por lo regular, consideran que tales decisiones son las que establecen qué

18 Hart, H. L. A., The Concept of Law...cit., p. 250 [para la versión en español, véase Hart, H. L. A., Post scriptum al concepto de derecho, trad. de Rolando Tamayo y Salmorán, México, UNAM, Instituto de Investigaciones Jurídicas, 2000, p. 26].

19 Leiter, Brian, "Legal Realism and Legal Positivism Reconsidered", Ethics, vol. 111, no. 1, Enero de 2001, pp. 278-301. 


\section{LA CONSTITUCIÓN DE E.U. Y LA REGLA DE RECONOCIMIENTO}

es lo jurídicamente válido -y, en esta contribución, se interpretan los términos 'jurídicamente válido' y 'derecho' en el sentido de que expresan la idea de que estas decisiones tienen el efecto de crear, mantener o extinguir derechos y deberes jurídicos aplicables-. Aun cuando hay un desacuerdo generalizado entre los oficiales sobre si la decisión de una Corte es 'correcta' en términos de derecho constitucional, los oficiales cooperan al tratar la decisión como derecho. Las agencias del orden público encargadas de implementar el derecho se niegan a hacerlo cuando una ley ha sido declarada inconstitucional, incluso si piensan que la decisión está equivocada. Los cuerpos legislativos relevantes podrian volver a promulgar la ley, pero esto no tiene efecto legal alguno. Otros tribunales rechazan, en términos jurídicos, cualquier acción fundamentada en una disposición que fue declarada inconstitucional por la Corte.

A pesar de la incesante controversia sobre el caso Roe, los oficiales lo consideran como derecho. Cualquier agencia gubernamental federal o estatal aplica a los criterios del caso Roe los mismos mecanismos coercitivos que utiliza cuando se trata de cualquier otra ley. En veces, los oficiales pueden intentar aprobar reglas que restringen el aborto de alguna manera, pero en todo momento obedecen a la Corte Suprema si anula tales reglas por considerarlas inconstitucionales. Los oficiales generalmente aceptan -aunque en ocasiones a regañadientes - que están obligados aun por decisiones de la Corte que creen que están equivocadas y, por ende, tratan el caso Roe como derecho, sin importar que crean que fue una decisión correcta o no.

Lo anterior no es casualidad. Como una cuestión de práctica jurídica, los oficiales generalmente consideran que tienen un deber institucional de respetar las decisiones sobre validez de la Corte que se emiten en el marco de su autoridad comúnmente aceptada. En el juicio Arizona c. Evans, por ejemplo, la Corte declaró que los "tribunales estatales, en los casos apropiados, no sólo tienen la libertad, sino que también tienen la obligación de interpretar la Constitución de los 
Estados Unidos..., [pero] no están más allá de la autoridad final de esta Corte". ${ }^{20}$ Aunque la Corte ha afirmado su autoridad sobre otros oficiales en otras ocasiones, tales recordatorios rara vez son necesarios porque los oficiales siempre coinciden en su expectativa de que todos ellos aceptan que las decisiones de la Corte establecen el derecho.

Esto tiene una consecuencia importante: dicha conducta indica que los oficiales practican de forma deliberada una regla de reconocimiento que le confiere a la Corte la autoridad final de decidir si una norma debidamente promulgada se ajusta a las normas sustantivas de la Constitución. En la medida en que la mayoría de los oficiales se asumen obligados incluso por las decisiones erróneas de la Corte, esto es porque coinciden en poner en práctica una norma de reconocimiento que impone un deber de segundo orden de considerar que las decisiones de la Corte establecen el derecho (según la forma en que el positivista entiende este término).

Los positivistas y los antipositivistas coinciden en esto. Como Hart lo señala, "Cuando [el tribunal supremo] ha dicho [qué es el derecho], el enunciado de que la corte estaba 'equivocada' no tiene consecuencias dentro del sistema: no se alteran los derechos o deberes de persona alguna". ${ }^{21}$ Como Dworkin lo expresa, la Corte "tiene el poder de invalidar hasta las decisiones más deliberadas y populares de otros departamentos del gobierno si cree que son contrarios a la Constitución, y por lo tanto tiene la última palabra sobre cuándo y cómo los Estados pueden ejecutar a los homicidas o prohibir abortos o establecer que haya oración en las escuelas públicas, sobre si el Congreso puede ordenar el reclutamiento de soldados para ir a la guerra u obligar al Presidente a publicar los secretos de su gestión”. 22

20 Arizona v. Evans, 514 U.S. 1 (1995), pp. 8 у 9.

21 Hart, H. L. A., The Concept of Law... cit., p. 141.

22 Dworkin, Ronald, Law's Empire..., cit., p. 2. Por supuesto, muchos teóricos creen que, como una cuestión de moral politica, la Corte no debe- 
Pero esto significa que la FID es incorrecta en tanto descripción empírica de los criterios de validez en los Estados Unidos de América. Mientras que la FID pretende validar todas y sólo aquellas normas debidamente promulgadas que se ajustan a las garantias sustantivas de la Constitución, los oficiales típicamente reconocen y tratan como derecho incluso aquellas decisiones sobre validez de la Corte Suprema que creen que son incorrectas en términos de derecho constitucional. Dado que, a fin de cuentas, los oficiales consideran que las decisiones de la Corte son las que resuelven el asunto relativo a cuáles normas debidamente promulgadas son jurídicamente válidas, la FID no es consistente con la conducta empírica de los oficiales y viola la limitación del ejemplo.

Uno podría responder a este argumento al señalar que lo que el derecho es en los Estados Unidos de América y lo que los oficiales implementan como derecho vienen por separado en los casos en los que la Corte comete un error en una decisión sobre validez, pero esta jugada no está disponible para un positivista. Si los criterios de validez son determinados por las prácticas empíricas de los oficiales, entonces las normas que éstos consideran de forma colectiva como jurídicamente válidas de acuerdo con una regla de reconocimiento de segundo orden, son jurídicamente válidas. Por lo tanto, la FID no puede ser reconciliada con la práctica oficial en los términos de la Tesis de Convencionalidad.

\section{Realismo juridico y la autoridad final de la Corte Suprema}

Otra postura natural va demasiado lejos en la dirección opuesta. Por ejemplo, John Chipman Gray sostiene que, en términos conceptuales, el derecho es lo que el máximo tribunal dice que es: "Para citar... a Bishop Hoadly: "Aquél que tiene la autoridad absoluta para interpretar cualquier

ría tener esta autoridad. Véase, por ejemplo, Waldron, Jeremy, Law and Disagreement, Oxford, Clarendon Press, 1999. 
derecho escrito o hablado, es el verdadero Dador de Derecho para todos los efectos y propósitos, y no la persona que lo escribió y habló en primer lugar"”. ${ }^{23}$ De acuerdo con esta postura, la autoridad final para decidir qué es el derecho lógicamente conlleva 'autoridad absoluta' que no puede ser jurídicamente limitada de ninguna manera.

En consecuencia, Gray infirió el argumento tristemente célebre de que la ley en los Estados Unidos de América es lo que la Corte Suprema dice que es, a partir de la tesis de que la Corte tiene autoridad final para decidir sobre la validez de las normas debidamente promulgadas. Toda vez que, según esta línea de análisis, la Corte tiene autoridad ilimitada para darle forma al contenido constitucional, los criterios de validez en los Estados Unidos de América incluyen la siguiente norma:

Formulación de Discreción limitada (FDI): Una norma debidamente promulgada es válida si y sólo si se ajusta a lo que la Corte Suprema decide respecto del contenido de las garantías sustantivas de la Constitución.

La FDI convierte a la Corte en el estándar y niega que la Constitución pueda genuinamente limitarla de manera alguna.

Hart rechaza explícitamente la postura de Gray al referirse a la Constitución de Estados Unidos de América, sobre la base de que la autoridad jurídica de la Corte sobre las decisiones de validez siempre está limitada por los significados determinados de la Constitución: "En todo momento los jueces, incluso los de un tribunal supremo, forman parte de un sistema cuyas reglas son lo suficientemente determinadas en su centro como para proporcionar estándares de decisiones judiciales correcta". ${ }^{24}$ Así, de acuerdo con Hart, la FDI pasa por alto el hecho de que la Corte está jurídicamente obligada a fundamentar sus decisiones sobre validez en el lenguaje de la Constitución y, por lo tanto, que jurídicamente la Corte se limita a interpretarla.

23 Chipman Gray, John, The Nature and Source of Law, Nueva York, The MacMillan Company, 1924, p. 125.

24 Hart, H. L. A., The Concept of Law..., cit., p. 145. 


\section{LA CONSTITUCIÓN DE E.U. Y LA REGLA DE RECONOCIMIENTO}

Hart está en lo correcto en cuanto a que hay límites al tipo de interpretaciones constitucionales que los oficiales están dispuestos a aceptar como los que establecen qué es y qué no es jurídicamente válido en todos los sistemas jurídicos existentes. Por ejemplo, una decisión de la Corte que invalida un limite federal de velocidad bajo el fundamento de que viola el derecho de la Segunda Enmienda de portar armas, probablemente provocaría una crisis constitucional sin precedentes en la historia de Estados Unidos de América. Más aún, una decisión de la Corte que invalida la legalidad del papel moneda bajo una teoría originalista probablemente sería ignorada y fuertemente criticada.

Al tomar en consideración el anterior comentario de Hart, uno podría pensar que, como cuestión empírica, los oficiales aceptan al menos la siguiente norma como la que limita la discrecionalidad de la Corte:

La Limitación de Aceptabilidad: Cuando determina si una norma es jurídicamente válida, la Corte Suprema tiene el deber de fundamentar sus decisiones en una interpretación de la Constitución que (1) pueda estar racionalmente fundada en el texto y (2) sea pragmáticamente aceptable.

Ahora estamos en posibilidad de utilizar un marco positivista para fundamentar una conclusión sobre la FDI que no sea controvertida entre la mayoría de los teóricos del derecho. En la medida en que la cantidad de interpretaciones plausibles define un limite convencional a la discrecionalidad de la Corte para emitir decisiones sobre validez, los oficiales de Estados Unidos de América, en términos empíricos, practican una norma de reconocimiento que incorpora la $\mathrm{Li}$ mitación de Aceptabilidad a la discreción de la Corte en la emisión de decisiones sobre validez. Dado que la Limitación de Aceptabilidad es una norma jurídica, restringe la toma de decisiones de la Corte al imponer un deber juridico de fundamentar sus fallos sobre validez en el texto de la Constitución. Mientras que los ministros supuestamente aceptan esta norma, los demás oficiales del sistema pueden ser libre- 
mente considerados como los que lo imponen desde el exterior; por lo tanto, me referiré a esto como un límite externo.

Entonces, en este punto podemos identificar los inicios de una regla de reconocimiento ( $\mathrm{y}$, por ende, de una norma jurídica) que define los deberes de los oficiales de respetar las decisiones de la Corte Suprema que satisfacen ciertos límites que son inconsistentes con la FDI:

Autoridad Final (AutFin): Los oficiales en los E.U.A. tienen (1) un deber de considerar como jurídicamente válidas aquellas normas debidamente promulgadas que han sido confirmadas por la Corte, en tanto se ajustan a una interpretación de la Constitución que satisface la Limitación de la Aceptabilidad y la Limitación $\Lambda$; y (2) un deber de considerar como jurídicamente inválidas las normas debidamente promulgadas que son anuladas por la Corte puesto que no se ajustan a una interpretación que satisface las referidas Limitaciones.

La locución "Limitación $\Lambda$ " sirve a modo de variable para otras limitaciones empíricas a la discrecionalidad de la Corte, si es que los hay, que los oficiales aceptan. Entonces, la AutFin es un esquema, cuyos detalles todavia necesitan ser completados.

De cualquier modo, el propio hecho de que AutFin incluye la Limitación de la Aceptabilidad a la discrecionalidad de la Corte, muestra cómo la FDI viola la Limitación del Ejemplo. Aunque la Limitación de la Aceptabilidad le fija un limite jurídico extremadamente modesto a la discrecionalidad de la Corte, la existencia de cualquier limite jurídico de este tipo es inconsistente con un enunciado sobre los criterios de validez que afirma que no hay ninguno. Entonces, la FDI viola la Limitación del Ejemplo.

3. La identificación de otros limites externos a la discrecionalidad de la Corte

Es razonable pensar que hay otros limites interpretativos a la discrecionalidad de la Corte además de la Limitación de 


\section{LA CONSTITUCIÓN DE E.U. Y LA REGLA DE RECONOCIMIENTO}

la Aceptabilidad. Aunque no podemos empezar a comprender la Constitución sin también entender los significados ordinarios de sus términos, éstos no pueden arrojar un resultado particular en ningún caso de validez que pueda ser ventilado ante la Corte. Y esto significa que la Limitación de la Aceptabilidad siempre le da un margen a la Corte para elegir una respuesta de 'sí' o 'no' a la pregunta sobre si una norma particular debidamente promulgada es jurídicamente válida.

Consideremos si la Corte debería o no confirmar una norma debidamente promulgada que prohíbe la pornografia infantil virtual. Es cierto que la Corte no puede entender la Primera Enmienda sin entender los significados ordinarios de términos como 'reducir' (abridge) y 'expresión' (speech), pero esto no pesa mucho como para orillar a la Corte a llegar a un resultado específico. El simplemente reunir los significados ordinarios de 'Congreso', 'no', 'podrá', 'hacer', 'ninguna', 'ley', 'limitando', 'libertad', 'de' y 'expresión' no nos dice casi nada sobre si la Primera Enmienda permite o no prohibir la pornografia infantil virtual. Dado que los significados ordinarios de la Primera Enmienda son indeterminados con respecto a la permisibilidad de una prohibición de la pornografia infantil virtual, la Limitación de la Aceptabilidad le otorga un margen total a la Corte de confirmar o anular la disposición según lo considere.

Aunque la Limitación de la Aceptabilidad contempla suficientes restricciones a la discrecionalidad de la Corte para refutar la idea de que la FDI es un criterio de validez, este limite realmente no influye mucho en determinar el resultado de los casos de validez. Siempre hay dos resultados lógicamente posibles en cualquier caso en el que se cuestiona la validez de una norma debidamente promulgada: la Corte puede ya sea confirmar la norma o anularla. Puesto que la Limitación de la Aceptabilidad excluye a un amplio número de interpretaciones irracionales del texto constitucional, permitirá que haya en cualquier caso 'difícil' tanto una interpretación racional que justifique el confirmar la norma, 
como una interpretación igualmente racional que justifique el anularla; pues, por definición, un caso es 'dificil' cuando el derecho existente no logra arrojar un resultado único. Toda vez que cualquier caso sobre validez que pueda llegar a la Corte Suprema es 'dificil' en este sentido, se sigue que la Limitación de la Aceptabilidad nunca eliminará un grupo lo suficientemente amplio de interpretaciones como para descartar, por lógica, una de las dos decisiones antagónicas. Luego, en esencia, la Limitación de la Aceptabilidad funciona para restringir a la Corte cuando justifica sus decisiones en casos dificiles sobre validez, pero no funciona para limitar los resultados que están disponibles para la Corte.

Es difícil reconciliar la práctica jurídica existente con la idea de que el único límite a la discrecionalidad de la Corte es el deber de fundamentar racionalmente sus decisiones en alguna interpretación plausible de la Constitución. Las decisiones sobre validez de la Corte siempre se basan en estándares interpretativos que requieren de bastante más que una conexión mínimamente racional a los significados ordinarios del texto constitucional. Cada uno de los enfoques dominantes hacia la interpretación constitucional, como el evolucionismo, el originalismo y el textualismo, pretenden identificar la mejor interpretación del texto y, entonces, una que sea superior a cualquier interpretación que sólo tenga una conexión mínima con los significados ordinarios del texto.

Esto sugiere que un enunciado preciso sobre los criterios de validez también debe tomar en cuenta la función que desempeñan estos estándares interpretativos sustantivos de restringir las determinaciones judiciales de lo que se considera como derecho. Como lo señala Kent Greenawalt:

Es dudoso que un estándar de interpretación que restringe a los jueces deba ser caracterizado como un estándar 'jurídico'. Algunos estándares de interpretación, como que las palabras ordinarias deben concordar con su significado natural en ausencia de una razón para hacerlo de otra manera, son 


\section{LA CONSTITUCIÓN DE E.U. Y LA REGLA DE RECONOCIMIENTO}

generales y fundamentales para todas las interpretaciones del lenguaje; pero otros estándares son claramente jurídicos o no lo son, siempre y cuando los jueces estén obligados a acatarlos cuando deciden qué significa la Constitución, necesita dársele algún lugar a los estándares entre los criterios últimos o derivados para determinar el derecho. ${ }^{25}$

Greenawalt cree que la regla de reconocimiento y los criterios de validez deben admitir el papel que desempeñan los principios jurídicos de interpretación, como por ejemplo los estándares originalistas o textualistas, en la determinación de lo que se considera derecho en los Estados Unidos de América.

No es de sorprender que Greenawalt le concede un lugar destacado a los estándares interpretativos 'dominantes' en la determinación de qué es lo que se considera derecho en los Estados Unidos de América al describir los criterios de validez. Él plantea esta cuestión en su propia descripción de la regla de reconocimiento de Estados Unidos de América de la siguiente manera: "En aquellos asuntos en los que no quede claro a partir del texto, los estándares dominantes de interpretación utilizados por la Corte Suprema son los que determinan qué es lo que significa la Constitución". ${ }^{26}$

Por supuesto, los estándares dominantes no pueden por sí mismos determinar completamente el resultado si las interpretaciones erróneas de la Corte son obligatorias, pero Greenawalt reconoce esto de forma explicita: "los oficiales generalmente tratan a una Constitución como si ésta fuese lo que los jueces supremos dicen que es". ${ }^{27}$ Consecuentemente, debería interpretarse que Greenawalt apoya la siguiente formulación:

25 Greenawalt, Kent, "The Rule of Recognition and the Constitution", en Adler, Matthew y Himma, Kenneth Einar (eds.), The Rule of Recognition and the U.S. Constitution, Nueva York, Oxford University Press, 2009, p. 33.

26 Ibidem, p. 36.

27 Ibidem, p. 31. 
Formulación de los Estándares Dominantes (FED): Una norma debidamente promulgada es jurídicamente válida si y sólo si en aquellas cuestiones que no quedan claras a partir del texto, se ajusta a lo que la Corte Suprema establece que significa la Constitución de acuerdo con los estándares de interpretación dominantes.

Aunque constituye un paso en pos de capturar adecuadamente la autoridad de la Corte en cuanto a la solución de las cuestiones de constitucionalidad, la FED no concuerda con las prácticas empíricas de los otros oficiales. Como el propio Greenawalt lo señala:

[El] decir que cualquier estándar actualmente dominante... forma parte de la regla suprema de reconocimiento... puede ser engañoso... Todos los Ministros creen que en ocasiones es adecuado alterar los estándares de interpretación anteriormente dominantes...28

No es sólo que los Ministros en ocasiones creen que es adecuado alterar esos estándares. Más bien, el punto es que la Corte tiene autoridad para alterar los estándares interpretativos al emitir decisiones sobre validez; si la Corte decidiera interpretar la Constitución basándose en las ideas populares, yo conjeturaria que otros oficiales aceptarian esos fallos y los implementarían. Pero si la Corte no está jurídicamente vinculada únicamente por los estándares 'dominantes', entonces se sigue que la Corte, como cuestión empírica, tiene autoridad legal para apartarse de esos estándares.

Esto, sin embargo, representa una dificultad para la FED. Si, desde el punto de vista empírico, la Corte tiene la autoridad para constreñir a los oficiales a través de decisiones que se apartan explícitamente de los estándares dominantes, ello ocurre porque los oficiales practican una norma que los obliga a tratar esas decisiones como las que establecen lo que es jurídicamente válido. Sin embargo, ya

28 Ibidem, pp. 33 у 34. 


\section{LA CONSTITUCIÓN DE E.U. Y LA REGLA DE RECONOCIMIENTO}

que, según el positivismo, lo que los oficiales colectivamente reconocen como jurídicamente válido sobre la base de que satisface un criterio general es en efecto jurídicamente válido, entonces de esto se sigue que cuando la Corte se aparta de los estándares dominantes al emitir decisiones sobre validez, está estableciendo a su vez lo que es jurídicamente válido. Puesto que la FED sostiene que sólo las decisiones que se fundamentan en estrategias interpretativas dominantes establecen lo que es jurídicamente válido, la FED viola la Limitación del Ejemplo y, por lo tanto, no tiene éxito en tanto descripción positivista de un criterio de validez en los Estados Unidos de América.

A estas alturas, el lector quizá ha notado un problema general con el hecho de formular límites externos a la discrecionalidad de la Corte. Mientras que algunas características sobresalientes de nuestra práctica jurídica sugieren que hay controles más estrictos para la discrecionalidad de la Corte que la Limitación de la Aceptabilidad, es de esperarse que sea más dificil identificar otros límites externos (i.e. límites primordialmente definidos por la cooperación de oficiales fuera de la Corte). Después de todo, los límites de la cooperación oficial rara vez, si es que del todo, han sido violadas por una decisión de validez de la Corte Suprema. En general, los oficiales de E.U.A. casi siempre han asumido que las decisiones de la Corte sobre constitucionalidad son las que establecen lo que es válido.

Es fácil conjeturar por qué sucede lo anterior. Una negativa por parte de otros oficiales a tratar las decisiones de la Corte como obligatorias probablemente indicaría una ruptura entre las diferentes ramas del gobierno, lo cual a su vez tendría profundas consecuencias para los componentes económico, psicológico y militar del bienestar nacional. ${ }^{29}$

29 Quizá esto no siempre ha sido así y posiblemente no será siempre así; quizá, no debería ser así. Pero, como cuestión empírica, generalmente se entiende dentro y fuera de los Estados Unidos de América, tanto por aliados como por enemigos, que las decisiones de la Corte Suprema son obligatorias para los otros oficiales. 
Por supuesto, una decisión que viola la Tesis de Aceptabilidad crea graves riesgos por sí misma, dado que sugiere una mala fe por parte de la Corte, y esto puede ser sintomático de un colapso gubernamental general; por eso es que resulta razonable suponer que otros oficiales se opondrian a implementar tales decisiones. Los riesgos que se asocian a un colapso entre la Corte y otros oficiales crean un fuerte incentivo para que otros oficiales asuman las decisiones de buena fe de la Corte (esto es, aquellas que satisfacen la Limitación de la Aceptabilidad) como obligatorias, sin importar qué tan profundamente equivocadas puedan estar.

\section{La función de las consideraciones morales como limites a la Corte}

En este punto, resulta útil intentar discutir en qué momento los Jueces de la Corte Suprema comienzan a fijar límites con respecto a lo que ellos están preparados a realizar. Puesto que lo que nos preocupan son las obligaciones de la Corte, podriamos tener mayor progreso al intentar identificar los límites impuestos por los estándares que los propios Jueces de la Corte Suprema aceptan como restricciones a su discrecionalidad en los casos constitucionales. Llamaré 'internos' a tales límites porque pareciera que los Jueces de la Corte se los imponen a sí mismos.

Aunque es un poco problemático, el análisis de Greenawalt indica una dirección muy natural en el propósito de identificar los límites internos a la discrecionalidad de la Corte y las normas de reconocimiento que expresan dichos limites. Los Jueces de la Corte claramente emplean una serie de estándares interpretativos que restringen su discrecionalidad, más allá de los que han sido definidos por la Limitación de Aceptabilidad. Entonces, un Juez que acepta uno de estos estándares considerará que está obligado a decidir los casos de validez de acuerdo con las interpretaciones constitucionales que satisfacen ese estándar. 
No obstante, la tarea de identificar la norma de reconocimiento relevante se complica por el hecho de que los Jueces de la Corte a menudo están en desacuerdo sobre cuáles estándares interpretativos son los apropiados. En cambio, si cada Juez considera que el originalismo es el único estándar legítimo de interpretación constitucional, los Jueces practicarian una norma que les exige decidir los casos de validez a partir de una perspectiva originalista. Pero, por supuesto, este no es el caso: mientras que algunos Jueces favorecen un enfoque originalista, otros prefieren un enfoque que considera a la Constitución como un "documento viviente"; e incluso otros favorecen un enfoque pragmático, al adoptar elementos de distintas estrategias según lo ameriten las circunstancias. En la medida en que los Jueces de la Corte consideren que las decisiones de ésta son obligatorias para los otros oficiales sin importar cuál de estos principios otorga una justificación en última instancia, una descripción de la norma de reconocimiento relevante no debería favorecer únicamente a uno de estos principios interpretativos.

Vale la pena destacar que los ministros se critican frecuentemente los unos a los otros por su selección de estrategias interpretativas dominantes. Por ejemplo, los originalistas a menudo critican a los teóricos del documento viviente por imprimir sus preferencias politicas en la Constitución de forma inapropiada, mientras que los teóricos de la Constitución viviente critican a los originalistas por adherirse a una visión del texto constitucional que carece de relevancia contemporánea. Sin embargo, en cada uno de estos casos la crítica es que la interpretación particular, aun si está fundamentada de forma plausible en algun estándar interpretativo dominante, no se fundamenta en la que en cierto sentido es la mejor interpretación de la Constitución.

Este tipo de críticas sugiere que los Ministros practican una norma de reconocimiento que requiere que la Corte fundamente sus decisiones sobre validez en la mejor inter- 
pretación de la Constitución. La explicación más coherente para el hecho de que los Ministros se critican los unos a los otros por no lograr obtener la mejor interpretación de la Constitución, es que se consideran obligados por esa interpretación al tomar decisiones y practican una norma que convierte a lo anterior en lo estándar.

Por supuesto, debería abundarse más en torno al sentido relevante del término 'mejor'. Por ejemplo, podría inferirse qué es 'mejor' desde un punto de vista de las políticas; o podría determinarse a partir de la perspectiva de la ambición personal. Así, mientras la tesis de que los Ministros se consideran a sí mismos como obligados a fundamentar sus decisiones sobre validez en la mejor teoría de interpretación constitucional debería ser eminentemente plausible, pues no podemos comprender exactamente a qué equivale esto sin una explicación de qué es lo que entiende por 'mejor'.

De manera algo sorpresiva, podemos traer a colación el trabajo derivado de la crítica más influyente del positivismo, para obtener una concepción teóricamente viable del sentido en el que es utilizado en la práctica sobre validez de la Corte. Dworkin lleva a cabo una serie de tesis empíricas sobre qué es lo que los jueces 'típicamente' hacen cuando resuelven casos dificiles. Dworkin observa que, por una cuestión general, los jueces perciben que están constreñidos por consideraciones moralmente normativas de legitimidad politica. ${ }^{30}$ De acuerdo con esta perspectiva, todas las clases de casos difíciles son típicamente decididas dependiendo de la fuerza de las consideraciones morales, y no del tipo de consideraciones normativas que fundamentan las decisiones legislativas. Los jueces en el sistema jurídico estadounidense adoptan una actitud interpretativa frente al derecho que consiste en interpretarlo en una manera consistente con el mejor punto de vista moral.

30 Aquí es importante recordar que la noción de legitimidad es de carácter moraly se ocupa de la medida en la que está moralmente justificado que el Estado utilice su fuerza coercitiva. 
Estos argumentos empíricos son bastante plausibles. Las opiniones y los desacuerdos de la Corte Suprema 'típicamente' sugieren que los Ministros pretenden interpretar la Constitución en una forma que legitima el sistema jurídico y su monopolio oficial del poder policíaco. Estas opiniones y desacuerdos frecuentemente cuestionan los argumentos y principios interpretativos de uno u otro tipo sobre la base de la moral política.

La cantidad de estrategias interpretativas que podrian ser incluidas bajo el rubro de 'moralmente mejores' es muy amplia. Por ejemplo, incluiría una teoría puramente orientada por resultados que simplemente intente alcanzar el mejor resultado moral, sin importar cualesquiera otra consideración, incluyendo las de legitimidad que se relacionan con la democracia. También incluiría la propia lectura moral de la Constitución de Dworkin, la cual requiere que los términos putativamente morales de la Constitución sean interpretados en el sentido de que incorporan las normas morales correspondientes. Pero también incluiría las teorías puramente historicistas, como el originalismo, que impide recurrir a la moral objetiva cuando se decide un caso a favor de una interpretación basada en una noción histórica de los términos; los originalistas, como Scalia, típicamente creen que el originalismo está justificado sobre la base de consideraciones de legitimidad moral. En efecto, aceptarían interpretaciones orientadas por el consecuencialismo, o, lo que es lo mismo, por cualquier método que consiste en varios aspectos de lo mismo. Al final del día, parece razonable pensar que todos los Ministros están empeñados en fundamentar sus decisiones en la mejor interpretación moral de la Constitución, y hay opiniones muy diferentes sobre cómo lograr esto.

Por ejemplo, en el caso Planificación Familiar c. Casey (Planned Parenthood $v$. Casey), ${ }^{31}$ la Corte sostuvo que, debido a ciertas consideraciones de legitimidad, necesitaba reafirmar el caso Roe:

31 Registro 505 U.S. 833. 
La legitimidad de la Corte depende de tomar decisiones jurídicamente ejemplares bajo circunstancias en las que ese carácter ejemplar sea lo suficientemente plausible como para que sean aceptadas por la Nación... Hay un... punto más allá del cual la revocación frecuente tensaría demasiado la creencia del país en la buena fe de la Corte... La legitimidad de la Corte se esfumaría con la frecuencia de su vacilación. ${ }^{32}$

Como respuesta, el Ministro Scalia sostiene que la afirmación de la mayoría en el sentido de que "la Corte debe adherirse a una decisión aun cuando ésta se enfrente a una 'fuerte oposición' y que por esa razón se encuentre ‘bajo fuego', adquiere un nivel de arrogancia casi zarista". ${ }^{33}$

No es casualidad que los Jueces de la Corte que conforman la mayoría y los disidentes se critiquen entre sí en términos de qué es lo legítimo. En un nivel más profundo, las perspectivas de esos Jueces sobre interpretación constitucional están usualmente basados en posturas normativas en torno a la legitimidad moral. Los defensores de enfoques textualistas y originalistas más conservadores típicamente rechazan las teorías más liberales de interpretación constitucional, en tanto las consideran inconsistentes con los principios morales que enfatizan la legitimidad de la toma de decisiones mayoritaria. El desdén de Scalia hacia los enfoques de Constitución viviente tiene un carácter indudablemente moral:

Esto no quiere decir que estoy en desacuerdo con [el argumento] de que el problema de la reformulación judicial de los textos adoptados de forma democrática está 'profundamente enraizado en nuestra historia' y que los 'jueces han ejercido ese tipo de autoridad supuestamente antidemocrática desde el inicio.' El reconocer lo anterior es simplemente aceptar que siempre ha habido, y siempre habrá, jueces caprichosos que

32 Planned Parenthood v. Casey, 505 U.S. en la p. 866.

33 Scalia, Antonin, A Matter of Interpretation, Princeton, Princeton University Press, 1997, pp. 131 y 132. Énfasis añadido. 


\section{LA CONSTITUCIÓN DE E.U. Y LA REGLA DE RECONOCIMIENTO}

tergiversan el derecho conforme a sus deseos. Pero reconocer el mal es una cosa, y aceptarlo es otra muy distinta... ${ }^{34}$

Queda claro que Scalia cree que las decisiones de la Corte que modifican la Constitución violan los ideales democráticos de la legitimidad: el permitirle a los jueces "ejercer autoridad antidemocrática" es un "mal" que amenaza "la existencia del gobierno democrático".

Por otra parte, los teóricos liberales no son menos propensos a fundamentar sus concepciones sobre lo que la Corte está legalmente obligada a realizar en consideraciones sustantivas de moral política. William Brennan rechazó el originalismo al considerarlo "arrogancia disfrazada de humildad" y defendió una norma interpretativa que proteja a los derechos individuales que se derivan de la dignidad humana:

En general, se han multiplicado los problemas de la relación de la ciudadanía con el gobierno, lo cual a su vez ha engendrado algunas de las cuestiones constitucionales más importantes de la actualidad. En tanto el gobierno actúa cada vez más profundamente en esas áreas de nuestras vidas que alguna vez se consideraban 'privadas', hay una necesidad cada vez mayor de velar por que los derechos individuales no sean restringidos o degradados en el interés de lo que en su momento parezca ser el 'bien público'. ${ }^{35}$

Mientras que la perspectiva de Scalia enfatiza la importancia de la toma de decisiones mayoritaria y, por ende, requiere una interpretación de la Constitución que sea puramente histórica y no moral, la postura de Brennan enfatiza la importancia de respetar los derechos individuales. Al igual que Scalia, Brennan formula el deber jurídico de la Corte como el de proteger ciertos ideales sustantivos de mo-

34 Planned Parenthood v. Casey, 505 U.S. en la p. 999.

35 Dicurso pronunciado por el Juez de la Corte William J. Brennan, reimpreso en The Great Debate: Interpreting Our Written Constitucion, Washington, D.C., Federalist Society, 1986, pp. 14 y 19 y 20. 
ral politica y favorece una interpretación de la Constitución llevada a cabo a la luz de estándares morales en evolución.

Tales observaciones empíricas sugieren que los Ministros están practicando la siguiente norma de reconocimiento de segundo orden:

Deber de Encontrar el Mejor Estándar de Interpretación (MejEst): Los Jueces de la Corte Suprema están obligados a resolver sobre la validez de normas debidamente promulgadas de acuerdo con la que es, en términos objetivos, la interpretación de la Constitución que sea moralmente la mejor.

Como lo indican sus escritos, los Ministros intentan (1) ajustar su comportamiento a una norma que les obliga a decidir casos conforme a la interpretación de la Constitución que sea moralmente la mejor y (2) adoptar el punto de vista interno hacia dicho estándar como el que gobierna su conducta en su calidad de oficiales.

Los otros oficiales también parecen adoptar el punto de vista interno frente al MejEst, aunque, en sentido estricto, los únicos deberes definidos por el MejEst corresponden a la Corte Suprema. Al igual que los Ministros de la Corte Suprema, los demás oficiales del sistema jurídico tienden a fundamentar sus perspectivas sobre cómo debería de decidir los casos la Corte en estándares de interpretación constitucional que están basados en perspectivas más generales sobre su función moralmente legítima en una sociedad democrática. Cuando los otros oficiales critican las decisiones erróneas de la Corte, dicha crítica se fundamenta inmediatamente en estas opiniones sobre cómo interpretar la Constitución y, en última instancia, se basan en la postura moral subyacente sobre el alcance de la autoridad legitima de la Corte conforme a los ideales democráticos. En consecuencia, la actitud y el comportamiento tanto de la Corte como de los otros oficiales parece convergir en MejEst.

Entonces, sobre la base de tales consideraciones, uno podria pensar que las interpretaciones de las normas constitucionales que son objetivamente mejores definen directa- 


\section{LA CONSTITUCIÓN DE E.U. Y LA REGLA DE RECONOCIMIENTO}

mente los criterios de validez. A partir de esta linea de análisis, lo siguiente es un criterio de validez en los Estados Unidos de América:

Formulación de la Interpretación que Objetivamente es la Mejor (FIOM): Una norma debidamente promulgada es jurídicamente válida si y sólo si se ajusta a la que moralmente es, en términos objetivos, la mejor interpretación de las normas sustantivas de la Constitución.

Si los oficiales en los Estados Unidos de América aceptan MejEst como lo que define los deberes de la Corte al efectuar decisiones sobre validez, entonces ello tiene que dar lugar automáticamente a un criterio de validez.

La FIOM viola la Limitación del Ejemplo al restarle importancia a la autoridad de la Corte para vincular a otros oficiales con sus decisiones. Si bien los otros oficiales criticarán a la Corte por no producir la que objetivamente es la mejor interpretación, aquellos oficiales aun así continuarán tratando las decisiones erróneas como derecho obligatorio. Puesto que en este sentido la Corte tiene una autoridad distintiva para obligar a otros oficiales a través de una de dos interpretaciones antagónicas de las disposiciones relevantes, una norma puede ser jurídicamente válida aun si, en términos fácticos, su contenido es inconsistente con la que objetivamente es la mejor interpretación de la Constitución. Por lo tanto, se sigue que las interpretaciones de las disposiciones sustantivas de la Constitución que objetivamente son las mejores, si es que las hay, no determinan directamente qué es lo que se considera como derecho en los E.U.A., aunque es cierto que funcionan como una restricción a la toma de decisiones de la Corte en los casos sobre validez.

\section{La formulación de la mejor interpretación} de la Corte de los criterios relevantes de validez

Dado que los oficiales aceptarán cualquier decisión de la Corte Suprema 
que satisfaga la Limitación de la Aceptabilidad y que, además, esté fundamentada en lo que la mayoría de los Ministros asumen como la interpretación de la Constitución que moralmente sea la mejor, pareciera que las normas de reconocimiento relevantes son la Limitación de la Aceptabilidad y el MejEst, y, por ende, que la norma de reconocimiento relevante que define los deberes de los oficiales en los Estados Unidos de América deberían ser formulados para completar la Limitación $\Lambda$ de la siguiente manera:

Autoridad Final (AutFin): Los oficiales en los E.U.A. tienen (1) un deber de tratar como derecho a aquellas normas debidamente promulgadas hasta que sean anuladas por la Corte por no ajustarse a la que colectivamente se considera como la mejor interpretación de la Constitución y que satisface la Limitación de la Aceptabilidad; y (2) un deber de tratar como no juridicas a aquellas normas debidamente promulgadas que son anuladas por la Corte al no ajustarse a la que colectivamente asumen que es la mejor interpretación que satisface la Limitación de la Aceptabilidad.

AutFin se adhiere más íntimamente con la práctica jurídica empírica porque reconoce que los oficiales aceptarán las decisiones de la Corte sobre cuál es la mejor interpretación en términos morales de la Constitución.

En consecuencia, un enunciado más preciso del criterio de validez supremo tendrá más o menos la siguiente apariencia:

La Formulación de la Mejor Interpretación de la Corte (FMIC): Una norma debidamente promulgada es juridicamente válida a menos de que sea declarada inconstitucional por aquella que la mayoría de los Ministros decide que es, objetivamente, la mejor interpretación en términos morales de las normas sustantivas de la Constitución.

De nueva cuenta, debería enfatizarse que hay varios temas que la autoridad de la Corte no abarca - como, por 


\section{LA CONSTITUCIÓN DE E.U. Y LA REGLA DE RECONOCIMIENTO}

ejemplo, asuntos que involucran cuestiones politicas- pero la Corte tiene autoridad final para decidir si un tema es una cuestión política o no. Por una parte, si la Corte se niega a abordar un asunto sobre la base de que lo cataloga como una cuestión política, ello es consistente con la FMIC. Pero, por otro lado, si erróneamente resuelve un caso que sí es catalogable como una cuestión politica, entonces los oficiales están obligados por ese fallo, lo que también es consistente con la FMIC.

Aunque son ciertamente vagas, la FMIC y la AutFin son mejores modelos de los hechos de la práctica de la Corte sobre validez que cualesquier otra formulación que hemos considerado. Al igual que la FED y la FDI, pero a diferencia de las otras formulaciones que se propusieron, la FMIC y la AutFin son consistentes con el hecho empírico de que, en cualquier caso dificil sobre validez, la Corte puede emitir su decisión en uno u otro sentido y así constreñir a los oficiales. Además, al igual que la FIOM pero a diferencia de las otras formulaciones, la FMIC y la AutFin son coherentes con el hecho empírico de que los Ministros y los otros oficiales aceptan el MejEst como el que define un deber de segundo orden por parte de la Corte de resolver los casos de validez de acuerdo con la interpretación de la Constitución que, en términos morales, es la mejor.

Si bien seguramente es posible mejorar la anterior formulación, para ser minimamente adecuada cualquiera de ellas tendrá que parecerse más a la FMIC y a FinAut que a las demás que hemos considerado, incluyendo la FID. Primero, toda vez que (1) lo que los oficiales reconocen como derecho es derecho y (2) los oficiales de los Estados Unidos de América típicamente tratan como derecho aun las decisiones equivocadas de la Corte respecto del contenido de las normas sustantivas de la Constitución, los criterios de validez en los Estados Unidos de América deben reflejar la autoridad discrecional de la Corte para darle forma al contenido de esas normas. Segundo, puesto que (1) la validez jurídica de la Corte está restringida por los estándares que los ofi- 
ciales en su conjunto aceptan como límites a lo que la Corte puede hacer en los casos sobre validez, y que (2) los oficiales de los Estados Unidos de América aceptan ciertos estándares que restringen la autoridad de la Corte para interpretar la Constitución; en consecuencia, los criterios de validez en los Estados Unidos de América tienen que reconocer que hay limites a la autoridad discrecional de la autoridad de la Corte en los casos sobre validez. Luego, si el positivismo está en lo correcto, entonces una descripción acertada del criterio relevante sobre validez tiene que reconocer tanto el hecho de que la Corte tiene una determinada autoridad discrecional para darle forma al contenido de la Constitución y el hecho de que hay limites a su autoridad.

\section{BIBLIOGRAFÍA}

AlEXANDER, Larry y ScHAUER, Fred, "On Extrajudicial Interpretation", Harvard Law Review, Vol. 110, 1997.

BRENNAN, William J. et al., The Great Debate: Interpreting Our Written Constitucion, Washington, D.C., Federalist Society, 1986.

CHIPMAN Gray, John, The Nature and Source of Law, Nueva York, The MacMillan Company, 1924.

Dworkin, Ronald, Law's Empire, Cambridge, Harvard University Press, 1986, p. 2 [Versión en español, Dworkin, Ronald, El imperio de la justicia, trad. de Claudia Ferrari, Barcelona, Gedisa, 1994].

DWORKIN, Ronald, Taking Rights Seriously, Cambridge, Harvard University Press, 1977, p. 32 [Versión en español, Dworkin, Ronald, Los derechos en serio, trad. de Marta Guastavino, quinta reimpresión, España, Ariel, 2002].

Dorf, Michael C. y ADLER, Matthew D., "Constitution Existence Conditions and Judicial Review," Virginia Law Review, Vol. 89, 2003. 
DORF, Michael C. y FRIEDmAN, Barry, "Shared Constitutional Interpretation", The Supreme Court Review, Vol. 2000.

EASTERBRoOK, Frank, "Presidential Review", Case Western Reserve Law Review, Vol. 40, 1989.

FALLON, Richard, "As-Applied and Facial Challenges and Third Party Standing”, Harvard Law Review, vol. 113, no. 6, 2000.

Greenawalt, Kent, "The Rule of Recognition and the Constitution", en Adler, Matthew y Himma, Kenneth Einar (eds.), The Rule of Recognition and the U.S. Constitution, Nueva York, Oxford University Press, 2009.

HART, H.L.A., The Concept of Law, 2a. ed. Oxford, Clarendon Press, 1994, p. 55 [versión en español, Hart, H. L. A., El concepto de derecho, 2a. ed., trad. Genaro R. Carrió, Editorial Nacional, México, 1980; también, Hart, H.L.A., Post scriptum al concepto de derecho, trad. de Rolando Tamayo y Salmorán, México, UNAM, Instituto de Investigaciones Jurídicas, 2000].

KRAMER, Larry, The People Themselves: Popular Constitutionalism and Judicial Review, Nueva York, Oxford University Press, 2004.

LEITER, Brian, "Legal Realism and Legal Positivism Reconsidered", Ethics, vol. 111, no. 1, Enero de 2001.

MEESE, Edwin, "The Supreme Court of the United States: Bulwark of a Limited Constitution", South Texas Law Review, vol. 27, 1986.

PAUlSEN, Michael Stokes, "The Most Dangerous Branch", Georgetown Law Journal, vol. 83, 1994.

SCALIA, Antonin, A Matter of Interpretation, Princeton, Princeton University Press, 1997.

WALDRON, Jeremy, Law and Disagreement, Oxford, Clarendon Press, 1999. 